\title{
Pedestrian safety in road traffic - studies, recommendations and proposed improvements
}

\author{
Marcin Budzyński ${ }^{1,}{ }^{*}$, Lucyna Gumińska ${ }^{1}$, Lukasz Jeliński ${ }^{1}$, and Mariusz Kieć ${ }^{2}$ \\ ${ }^{1}$ Gdansk University of Technology, Faculty of Civil and Environmental Engineering, Gdansk, Poland \\ ${ }^{2}$ Cracow University of Technology, Faculty of Civil Engineering, Cracow, Poland
}

\begin{abstract}
Pedestrians are involved and most frequently the victims of every third road accident in Poland. Pedestrian accidents most frequently occur in complex circumstances, as a result of many factors related to the behaviour of drivers and pedestrians. The basic parameters that determine road safety include the perception of traffic and visibility on the road. The paper will present the results of research conducted within the project commissioned by the National Road Safety Council Secretariat titled "The methodology of systematic study on pedestrian behaviour and pedestrian - car driver relations". The authors will present the impact of location, type of crosssection and other selected parameters on the behaviour of drivers and pedestrians in the area of pedestrian crossings. The paper will also present recommendations for the design of pedestrian crossings and monitoring road user behaviour at pedestrian crossings.
\end{abstract}

\section{Introduction}

Every third road accident in Poland involves a pedestrian as a participant or, most of the time, a casualty. Pedestrian accidents are usually the result of complex situations and the outcome of a number of factors related to driver and pedestrian behaviour and road infrastructure. Safety depends largely on how well the traffic condition is perceived and on visibility in traffic. The paper presents the results of analyses of methodologies for systematic studies of pedestrian behaviour and pedestrian-driver relations (for the Secretariat of the National Road Safety Council) [1]. The effects of the location of the site, type of cross-section and other selected parameters on pedestrian and driver behaviour are demonstrated. Recommendations for pedestrian crossing design are also provided.

\section{Method for systematic studies of pedestrian-driver behaviour}

\subsection{Study description}

The main objective of the work was to develop a methodology for systematic studies of pedestrian behaviour and pedestrian-driver relations [2-11]. The aim is to make walking more attractive and improve pedestrian safety. The work involved tests on site and surveys in 69 test points across the regions of Pomorskie and Małopolskie. The areas vary in terms of the development, road cross-section and location of pedestrian crossings (Fig. 1).

* Corresponding author: mbudz@.pg.edu.pl 


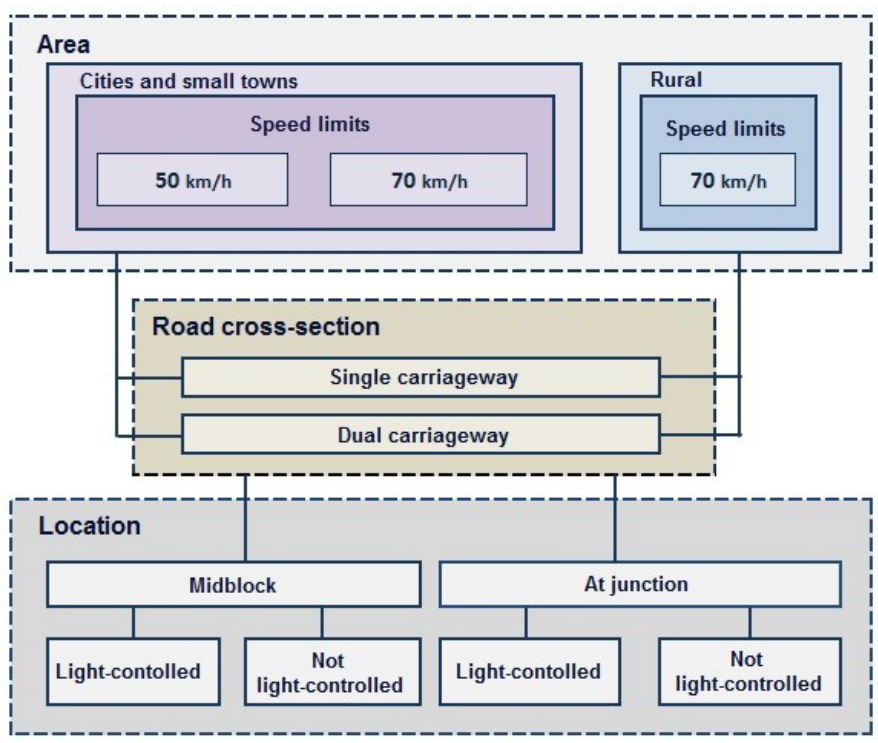

Fig. 1. Diagram of test points selection [1].

One of the site parameters was the speed of vehicles approaching the pedestrian crossing. A set of digital cameras were used for top quality recording. The location of the cameras made sure that they covered the entire crossing as well as the approach (app. $100 \mathrm{~m}$.) with test point cross-sections spaced every $10 \mathrm{~m}$. They were then used to elaborate vehicle speed profiles in the following situations: pedestrian waiting to cross the road, pedestrian crossing the road and no pedestrians on or around the crossing. In addition, vehicles in free-flow and selected pedestrian and driver behaviours were taken into account.

As well as studying pedestrian behaviour, the project also looked at the distance between the pedestrian and road as they wait to move onto the crossing, whether the pedestrian checked the traffic situation before or during crossing the road and pedestrian age structure and sex. In addition, a survey was conducted among pedestrians after they had crossed the road and among drivers who were parked close to the test points. The objective was to identify the main problems as perceived by pedestrians and drivers and identify driver behaviour on pedestrian crossings based on the situations depicted below (Fig. 2).
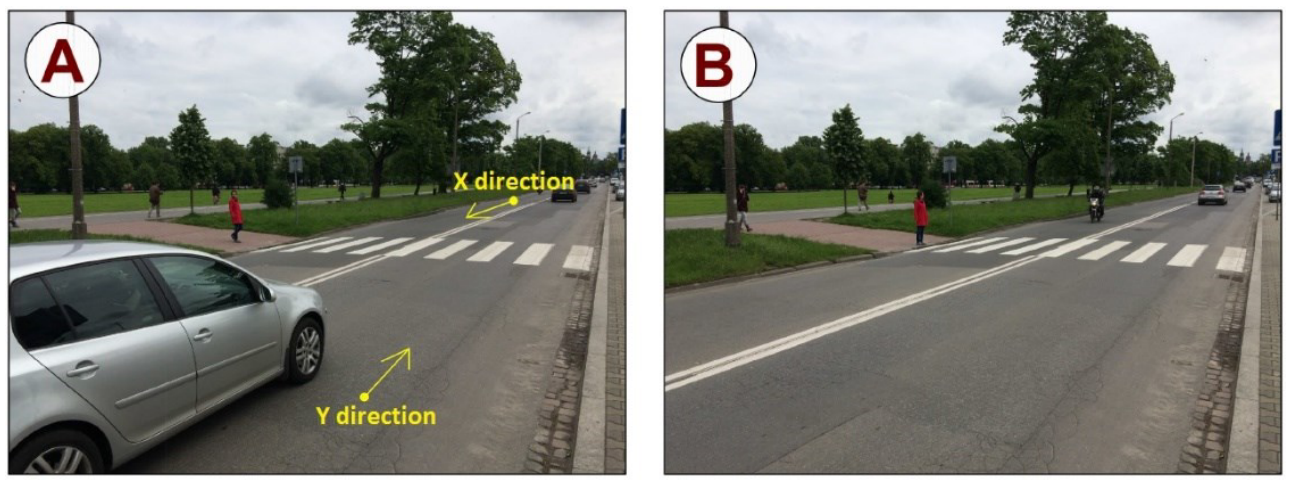

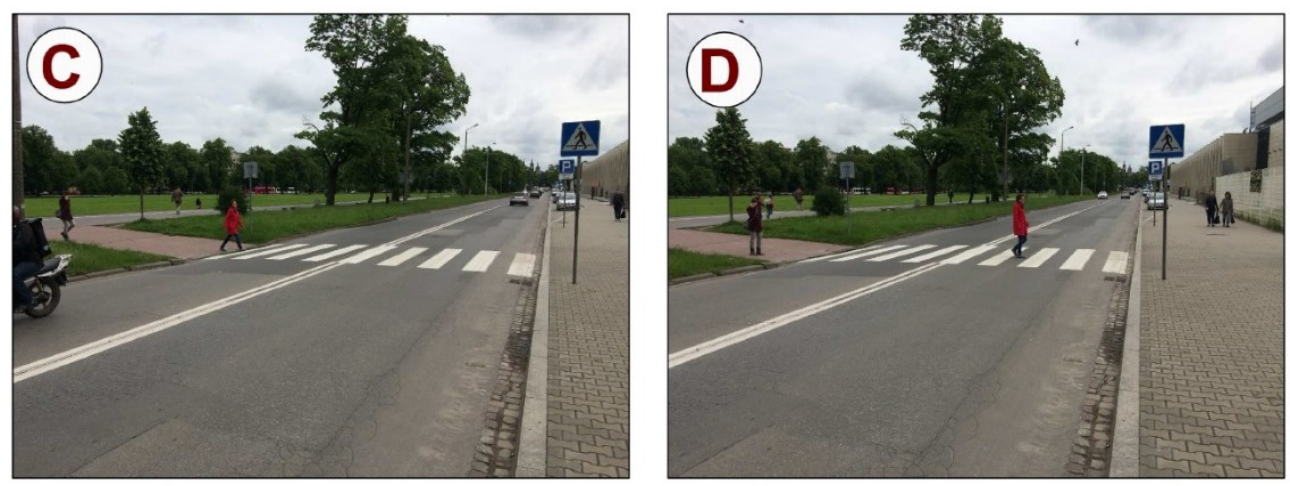

Fig. 2. Situations presented to surveyed drivers [1]: A) pedestrian approaching the crossing, B) pedestrian waiting before the crossing, C) pedestrian moving onto the crossing, D) pedestrian on the crossing.

\subsection{Study results}

The data collected (video footage) were used to analyse driver behaviour. It was found that when traffic is light-controlled, $3 \%$ of drivers do not stop for the red light as required. In 50 $\mathrm{km} / \mathrm{h}$ areas (test points in towns and villages) app. $40 \%$ of drivers exceed the speed limit (Fig. $3 \mathrm{a})$ and in non-built-up areas with a speed limit of $70 \mathrm{~km} / \mathrm{h}$, app. $30 \%$ of drivers go over the prescribed speed limit (Fig. 3b), a clear indication of the need to apply speed management solutions and enforcement.

In towns and villages for all types of cross-sections, vehicle speeds are lower if pedestrians are waiting to cross as opposed to where there are none (by $16 \mathrm{~km} / \mathrm{h}$ for $1 \times 2$ lanes cross-section, by $16 \mathrm{~km} / \mathrm{h}$ for $1 \times 4$ lanes, by $2 \mathrm{~km} / \mathrm{h}$ for $2 \times 2$ lanes and $2 \times 3$ lanes). The lowest speed on approaching a crossing with no pedestrians waiting, at $10 \mathrm{~m}$ from the crossing was recorded for the $1 \times 2$ lanes cross-section with a refuge island $(30 \mathrm{~km} / \mathrm{h}$ less than for $1 \times 4$ lanes, $23 \mathrm{~km} / \mathrm{h}$ less than for dual carriageways (Fig.4). The lowest speed on approaching a crossing with pedestrians waiting was recoded for $1 \times 2$ lanes cross-section with no refuge $(16 \mathrm{~km} / \mathrm{h}$ less than for $1 \mathrm{x} 4$ lanes, $22 \mathrm{~km} / \mathrm{h}$ less than for dual carriageways). The lowest speed on approaching a crossing being crossed by a pedestrian was recorded for $1 \times 2$ lanes with a refuge but the differences between the cross-sections are quite small.

a)

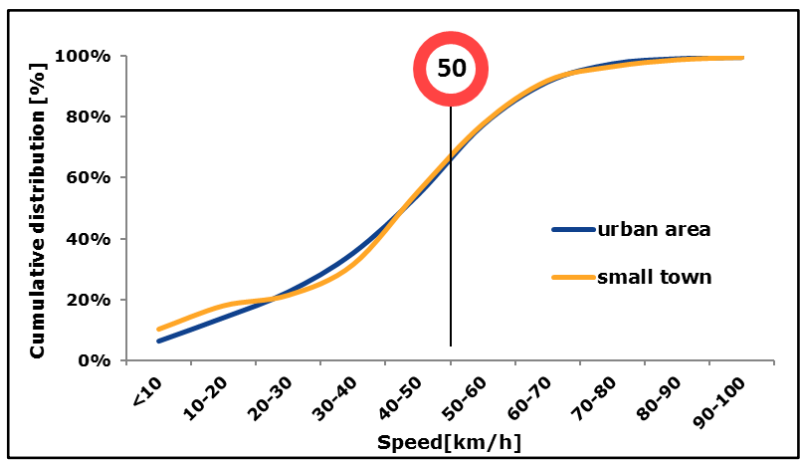


b)

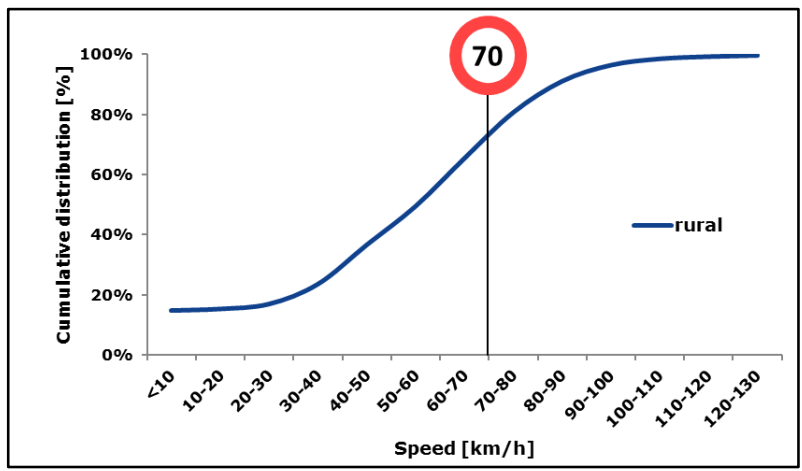

Fig. 3. Cumulative distribution of speed $10 \mathrm{~m}$ before the pedestrian crossing a) in towns and villages $-\mathrm{V}=50 \mathrm{~km} / \mathrm{h}, \mathrm{b}$ ) non-urban areas $-\mathrm{V}=70 \mathrm{~km} / \mathrm{h}[1]$.

a)

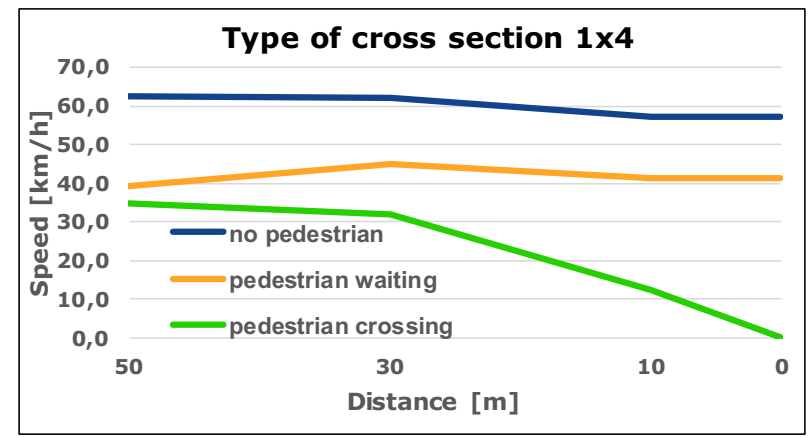

b)

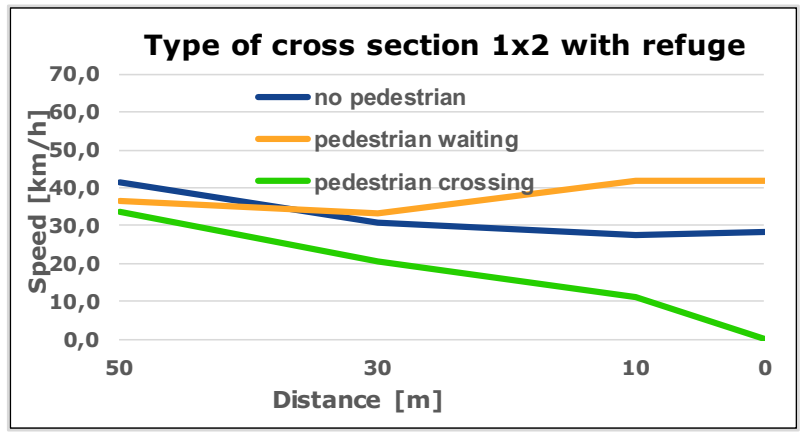

Fig. 4. Characteristics of vehicle speeds on approaching pedestrian crossings for selected crosssections [1].

Seven and a half thousand drivers were surveyed. A clear majority of the respondents believed that you have to stop before the crossing if the pedestrian is before the kerb $(89 \%)$ and when the pedestrian is already on the road (99.7\%). They also believed that drivers fail to stop in these cases $(60 \%)$. In selected test points drivers were observed to establish their real behaviour in situations pictured in the photos (Fig. 2). Survey results were compared against driver observations which showed that in reality many more drivers fail to stop and give way to a pedestrian who is either waiting to cross the road or has just moved onto the crossing (as opposed to what was declared in the survey) (Fig. 5 ). 


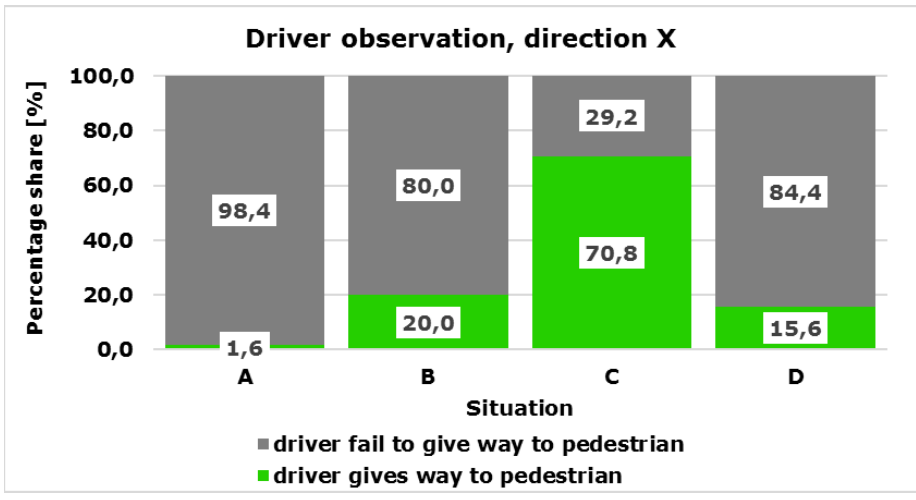

Fig. 5. Results of driver observations (Situations A, B, C, D - Fig.2) [1].

\section{Selected recommendations for improving pedestrian safety}

The analyses showed that pedestrians are most often put at risk by too long pedestrian crossings, vehicles going too fast around pedestrian crossings, lack of proper sight distance and poorly lit or unlit pedestrian crossings. The reason for such defective infrastructure is that planners, designers, contractors and maintenance services are not receiving any support from design, marking and maintenance regulations for pedestrian traffic. In addition, the Road Traffic Law is not restrictive enough when it comes to drivers' obligations towards pedestrian safety.

First, a method must be introduced to ensure a match between type of pedestrian crossing and speed limit. Because speed limits are generally exceeded everywhere in the country, it is recommended to use the percentile $\mathrm{V}_{85}$ of measured speed. A stock-taking of the infrastructure showed that many pedestrian crossings have $50,60,70 \mathrm{~km} / \mathrm{h}$ speed limits and as much as $90 \mathrm{~km} / \mathrm{h}$ in non-built-up areas. This applies to crossings that stretch over two lanes and more. The Pedestrian Safety Handbook [12] points out (Fig. 6) that a safe speed is 30 $\mathrm{km} / \mathrm{h}$. Speeds between 30 to $50 \mathrm{~km} / \mathrm{h}$ are moderately safe. The relation between the probability of a vehicle hitting a pedestrian and the probability of pedestrian death shows a $50 \%$ chance of survival when the pedestrian is hit by a vehicle going at about $50 \mathrm{~km} / \mathrm{h}$. Thus, anything above $50 \mathrm{~km} / \mathrm{h}$ is considered dangerous and speeds above $70 \mathrm{~km} / \mathrm{h}$ are considered critical. This should be the basis for planning types of pedestrian crossings.

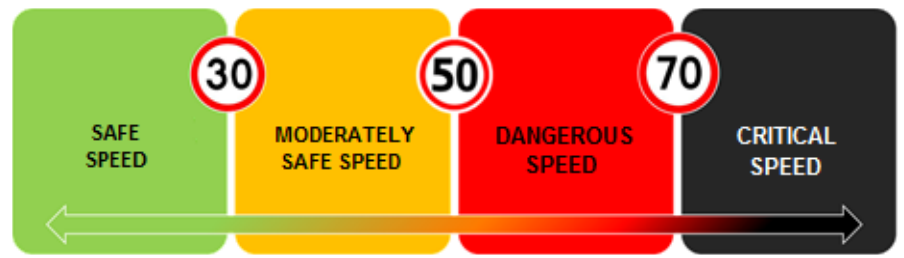

Fig. 6. Speed classification for pedestrian safety [2].

Polish design regulations [13] allow long pedestrian crossings up to four lanes in one direction or three lanes in two directions irrespective of traffic control and speed limits. Pedestrian crossings should be kept at a maximum of three lanes. There is nothing in the design regulations about the required driver-pedestrian sight distance. Neither does the Road Traffic Law [14] (art. 49.1.2) help engineers with that. It is legal to park vehicles within 10 $\mathrm{m}$ of a pedestrian crossing which does not guarantee the necessary sight distance. Drivers must be able to see a pedestrian waiting or stepping onto the crossing from a distance that will help them come to a stop safely. It is safer to follow the principle of providing adequate 
pedestrian sight distance. A pedestrian crossing the road should be able to judge thanks to the sight distance that there is a safe time gap to allow them to cross safely (Fig. 7).

a) pedestrian sight distance

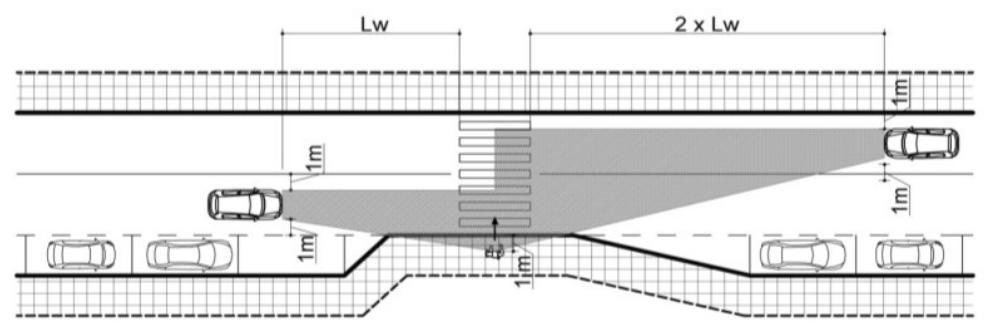

b) driver sight distance

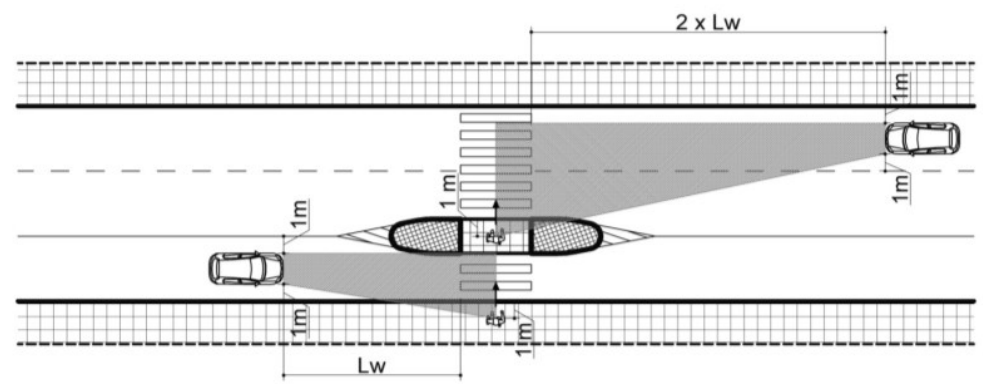

Fig. 7. Proposed principles for determining sight distance on pedestrian crossings [12].

Good sight distance $L_{w}$ of a vehicle coming from the right or left side of a pedestrian is determined depending on: percentile $\mathrm{V}_{85}$ measured within the area of the pedestrian crossing, width of the pedestrian crossing (number of lanes to be covered by the pedestrian) and pedestrian speed $V_{p}$. Initial tests have shown that optimal vehicle sight distance for percentile $\mathrm{V}_{85}=50 \mathrm{~km} / \mathrm{h}$ is $45 \mathrm{~m}$.

To improve pedestrian safety on crossings, long crossings must be related to the volume of motorised traffic, pedestrian traffic and the actual speed of vehicles and sight distances. Safe speed cannot be higher than $50 \mathrm{~km} / \mathrm{h}$. In addition, clearance for parking must be checked in relation to the speed limit to ensure proper sight distance. Road safety management must be implemented $[15,16]$ to provide pedestrian safety when designing and using road infrastructure.

\section{Conclusions}

Walking plays a crucial role in the transport system. This is true of small towns and villages with very little public transport and of big cities where walking is often used to move around the city. Walking is also part of many people's everyday lives (especially children, school youth, older people, people who do not have a car). Having said this, pedestrians are the most vulnerable road users and most at risk of death in road accidents, representing more than $30 \%$ of all road accident fatalities in Poland.

The relations between walking and driving and the hazards generated should be further researched to ensure that pedestrians can use roads safely.

The pedestrian-driver relation and the behaviour must be monitored on an on-going basis and pedestrian crossings must be inspected for safety. This will help improve pedestrian safety effectively. 


\section{References}

1. K. Jamroz, M. Budzynski., S. Gaca, M. Kiec, et al., Methodologies for systematic studies of pedestrian behaviour and pedestrian-driver relations (Secretariat of the National Road Safety Council, 2015)

2. I.P. Alonso, D.F. Llorca, M.A. Sotelo, et al., Combination of Feature Extraction Methods for SVM Pedestrian Detection, IEEE. 8 (2007)

3. K. Diependale, Do pedestrians comply with traffic lights in Belgian cities?, in: ICTCT Work., (Ashdod, Israel, 2015)

4. B. Fildes, S. Lee, D. Kenny, W. Foddy, Survey of older road users: behavioural \& travel issues - Report \#57 (Monash University Accident Research Centre, 1994)

5. P.E. Gårder, The impact of speed and other variables on pedestrian safety in Maine, Accid. Anal. Prev. 36 pp. 533-542 (2004). doi:10.1016/S0001-4575(03)00059-9

6. J. Hatfield, R. Fernandes, R.F.S. Job, K. Smith, Misunderstanding of right-of-way rules at various pedestrian crossing types: Observational study and survey, Accid. Anal. Prev. 39 pp. 833-842 (2007). doi:10.1016/j.aap.2006.12.005

7. C. Johansson, Towards a method to improve road safety for pedestrians and cyclists especially in child pedestrian environments, Luleå University of Technology, Department of Civil, Environmental and Natural Resources Engineering, Architecture and Water, 2001

8. P.Olszewski, I.Buttler, W.Czajkowski, P.Dąbkowski, C.Kraśkiewicz, P.Szagała, A.Zielińska, Pedestrian safety assessment with video analysis, Transp. Res. Procedia. 14 pp. 2044-2053 (2016)

9. N. Guéguen, S. Meineri, C. Eyssartier, A pedestrian's stare and drivers' stopping behavior: A field experiment at the pedestrian crossing, Saf. Sci. 75 pp. 87-89 (2015). doi:10.1016/j.ssci.2015.01.018

10. E. Papadimitriou, A. Theofilatos, G. Yannis, Patterns of pedestrian attitudes, perceptions and behaviour in Europe, Saf. Sci. 53 pp. 114-122 (2013). doi:10.1016/j.ssci.2012.09.008

11. P. Tomczuk, Pedestrian safety - luminance measurements at a pedestrian crossing, Constr. Archit. 13 (2014)

12. K. Jamroz, S. Gaca, L. Michalski, M. Kieć, M. Budzyński, L. Gumińska, W. Kustra, T. Mackun, I. Oskarbska, J. Rychlewska, A. Ryś, J. Wachnicka, J. Wierzbicka, Ochrona Pieszych. Podręcznik dla organizatorów ruchu pieszego (Protection of Pedestrians. Guidelines for pedestrian traffic organizers) (National Road Safety Council, Gdansk, Warsaw, Cracow, 2014)

13. Regulation of the Minister of Transport and Maritime Economy of 2 March 1999 on technical conditions for public roads and their location, OJ 1999 No. 43 Pos. 430 (Poland, 1999)

14. Act of 20 June 1997 Road Traffic Act no. 98 pos. 3113 (Poland, 1997)

15. K. Jamroz, M. Budzyński, W. Kustra, L. Michalski, S. Gaca, Tools for road infrastructure safety management - Polish experiences, in: Transp. Res. Procedia, pp. 730-739 (2014). doi:10.1016/j.trpro.2014.10.052

16. K. Jamroz, M. Kiec, W. Kustra, Protection of Pedestrians as the Key Action for Implementing Poland's Vision Zero, paper 15, 0691, in: TRB 94th Annu. Meet., (Washington DC, 2015) 